Advances in Gene Technology: The Genome and Beyond -

Structural Biology for Medicine (Proceedings of the 2002 Miami

Nature Biotechnology Winter Symposium)

TheScientificWorld 2002, 2(S2), 13-14

ISSN 1532-2246; DOI 10.1100/tsw.2002.7

\title{
GENETIC MODELS OF AEROBIC ENDURANCE RUNNING CAPACITY IN RATS
}

\author{
Steven L. Britton and Lauren Gerard Koch \\ Functional Genomics Laboratory, Medical College of Ohio, 3035 Arlington Avenue, Toledo, \\ Ohio 43614-5804 \\ sbritton@mco.edu
}

INTRODUCTION. The accumulation of atmospheric oxygen starting about 2 billion years ago was permissive for the evolution of complex aerobic metabolic pathways[1,4]. It is thus axiomatic that aerobic capacity defines both a large part of our biology and a divide in the continuum between health and disease[2]. While heritability studies predict a genetic component that accounts for as much as 70 to $90 \%$ of the variation in aerobic capacity[3], the genes causative of the difference between low and high capacity have not been defined. In 1996 we started artificial selection for low and high aerobic treadmill-running capacity in rats. The purpose was to create low-capacity runners (LCR) and high-capacity runners (HCR) that could ultimately be developed into contrasting strains for intrinsic (i.e., untrained) aerobic capacity. Here we report the response to selection across nine generations of divergent artificial selection for aerobic treadmill-running capacity.

METHOD. Artificial selection for intrinsic, aerobic, endurance-running capacity was started using the genetically heterogeneous N:NIH stock of rats as a founder population $(\mathrm{n}=168)$. Selection for low and high capacity was based upon distance run to exhaustion on a motorized treadmill using a velocity-ramped running protocol.

RESULTS. On average the founder population ran to exhaustion in $355 \pm 11 \mathrm{~m}$. Nine generations of selection produced lines that differed in running capacity by $270 \%$ with most of the change occurring in the high line (HCR). At generation nine, the LCR ran $230 \pm 8 \mathrm{~m}$ and the HCR ran $851 \pm 36 \mathrm{~m}$ at exhaustion.

DISCUSSION. The large difference (270\%) in capacity between the LCR and HCR demonstrate that these will be useful models for discovering the genes responsible for variation in intrinsic aerobic capacity. Our immediate plan is to increase the intensity of selection to produce LCR and HCR that are even more widely (greater than fivefold) different in running capacity and make these available for study. Long term, we will create at least four inbred lines for both LCR and HCR. 


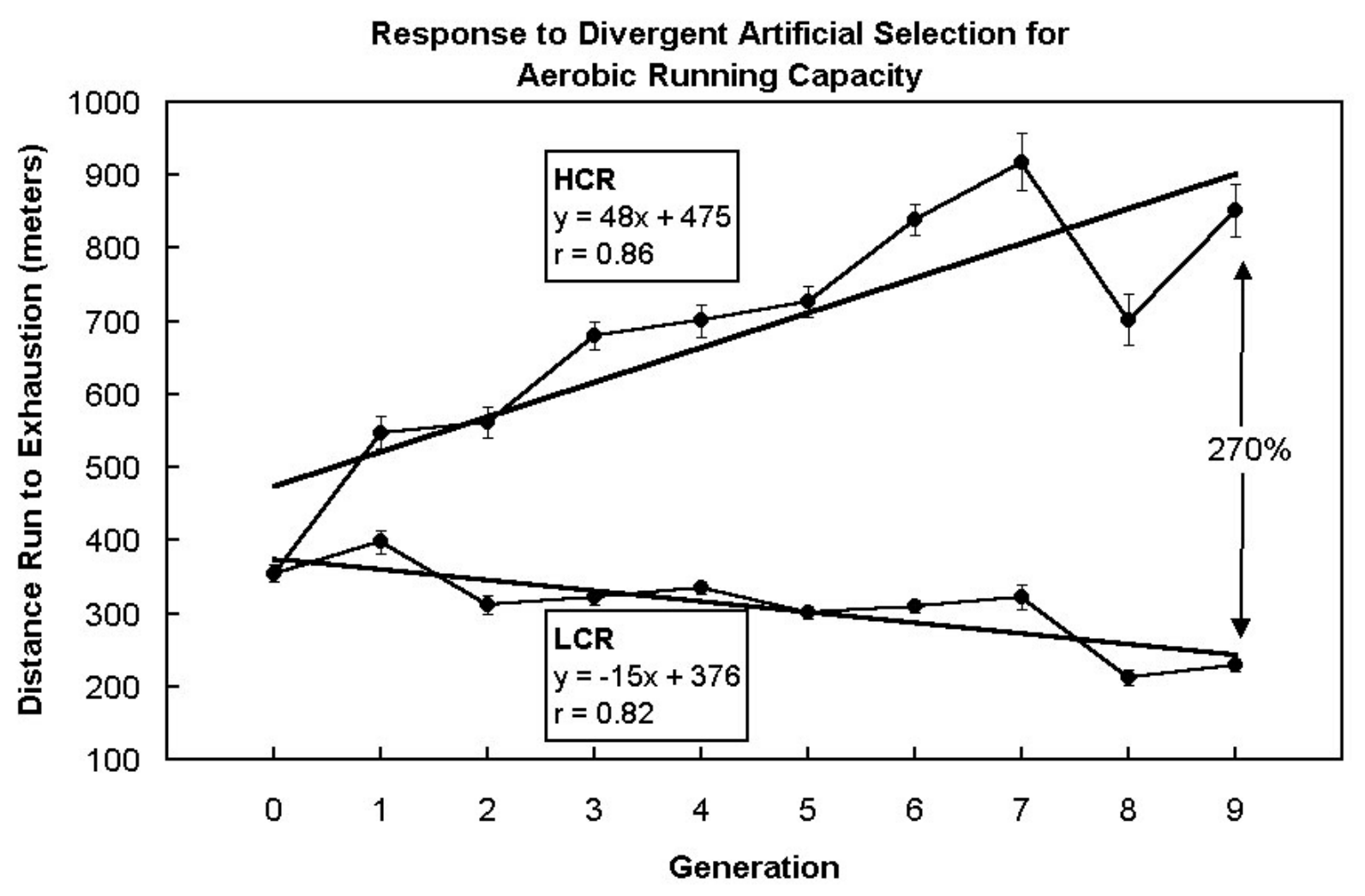

ACKNOWLEDGEMENTS. Supported by National Institutes of Health Grant HL64270.

\section{REFERENCES}

1. $\quad$ Baldwin, J.E. and Krebs, H. (1981) Nature 291, 381-382.

2. $\quad$ Fisher, R.A. (1930) Clarendon Press, Oxford, England.

3. $\quad$ Klissouras, V. (1971) J. Appl. Physiol. 31, 338-344.

4. Paytan, A. (2000) Science 288, 626-627. 

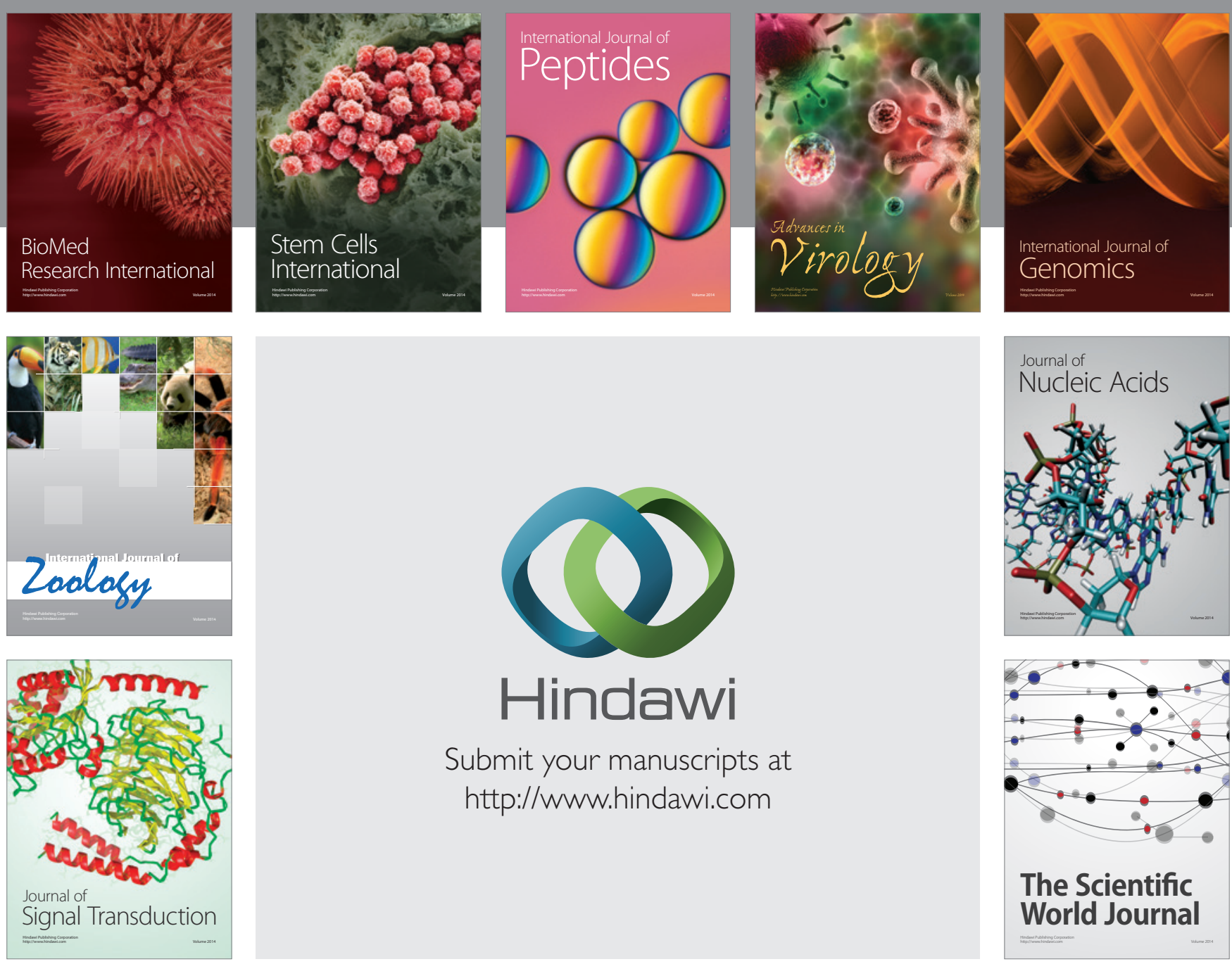

Submit your manuscripts at

http://www.hindawi.com
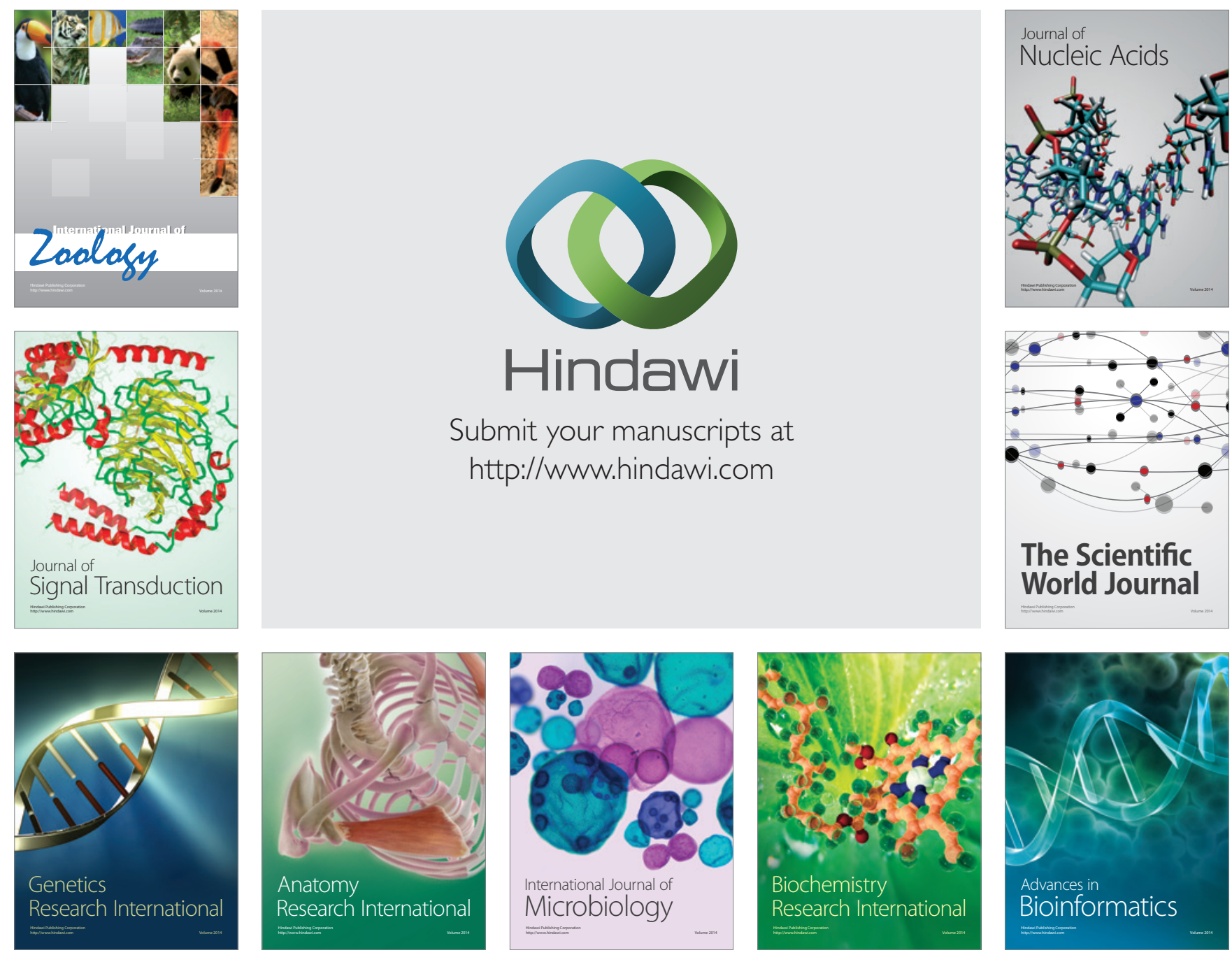

The Scientific World Journal
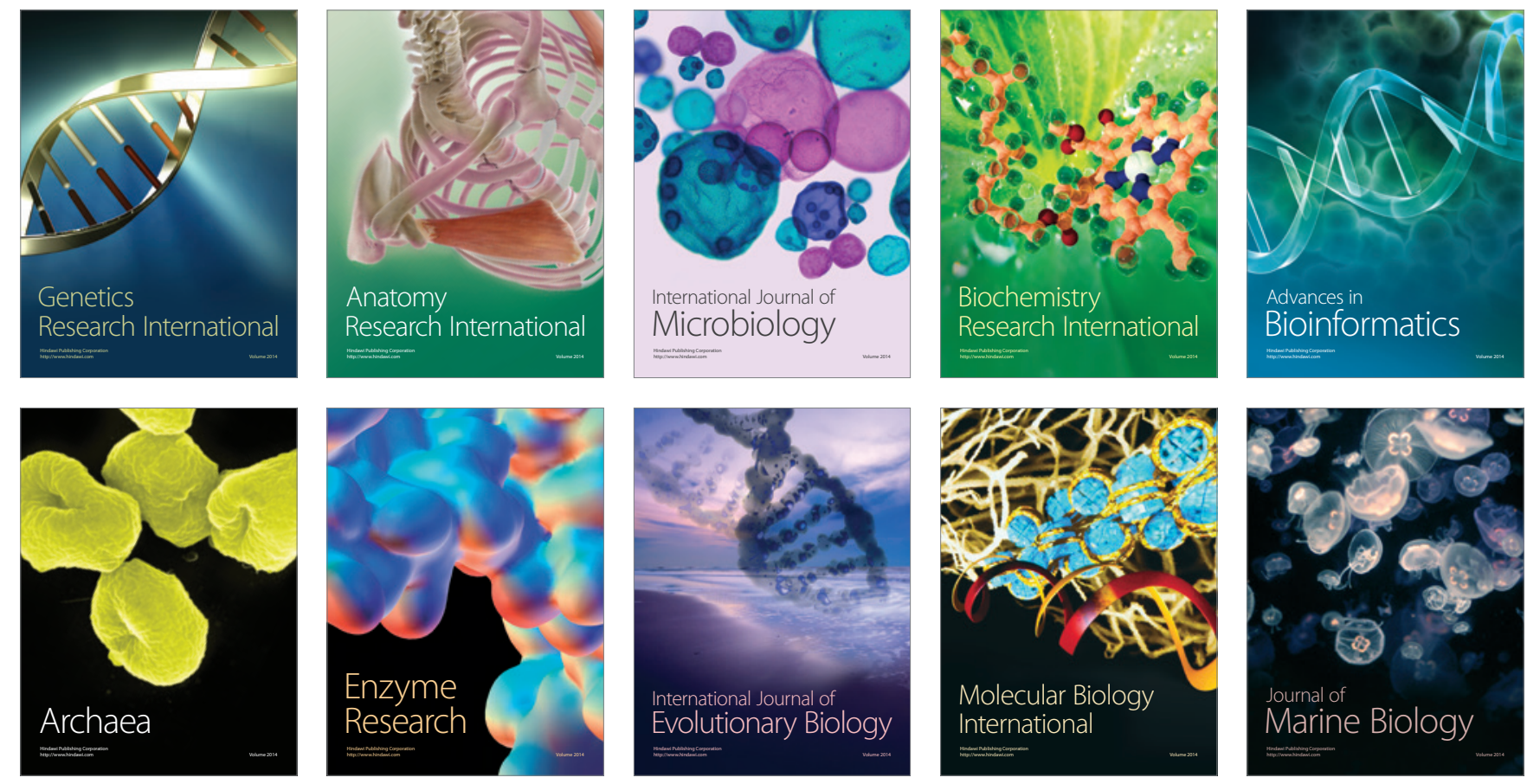